\title{
ANALYSIS OF THE EFFECTS OF THE ROOFING DESIGN ON HEAT STRESS IN DAIRY COW HOUSING
}

\author{
Paolo Liberati
}

\section{Introduction}

In animal housing the roof plays a primary role in the determination of thermal exchanges of the animals $[7,15]$. In particular, a high thermal resistance in daily hours can be helpful in a hot climate in order to reduce the effects of solar radiation [2,3]. But an increased thermal resistance reduces the capacity of discharging heat through the roof in the night hours [7,9].

In order to reduce the diurnal negative effect of the radiative heat load the use of insulating materials is normally recommended. But this is an expensive solution and its usefulness has not been confirmed, depending on various factors: climate, latitude, building geometry and orientation, constructive solutions, animal physical and spatial parameters $[4,5,6]$.

In dairy housing, many real buildings can be seen all over the world where the roof insulation [13] is avoided and the reduction of the solar effect simply pursued throughout some geometrical parameters: slope, height, open ridge [9].

This study aims at investigating the effective influence of the roof constructive parameters on the animal heat exchange (and welfare) during the whole day, trying to find out the optimal solutions for different combinations of the more relevant factors: insulation, slope, orientation, height, shape.

The work, carried out by a specific theoretical model, is in this paper referred to a location in the North of Italy (Po valley), but it can be equally applied to other different climate and latitude conditions.

\section{Materials and Methods}

A simulation model determining the heat flow exchange between housed animals and the roofing was

\footnotetext{
Paper received 02.01.2008; accepted 29.07.2008
}

PaOlo Liberati, Department of Crop Protection and Valorisation (DIPROVAL), University of Bologna, Via f.lli Rosselli 107, 42100 Reggio Emilia, Italy. paolo.liberati@unibo.it developed considering various relevant factors: constructive materials, slope, height, orientation, latitude, external air temperature, solar load, animal position, and not only geometrical aspects [8].

The model was applied with reference to climatic conditions of Northern Italy (31 ${ }^{\text {th }}$ of July), to dairy cows, and to a fully open building (a simple shelter). For closed buildings (the dynamic model can work also with these buildings) the effect on the animal heat exchange would be much higher since the heat exchanged throughout the roof influences the animal not only directly in a radiative form, but also in a convective form, by increasing or decreasing the internal air temperature.

The view factor between the roof and a hypothetical cow underneath was calculated considering different parameters: roof slope, eaves height, roof type (gabled and multi shed roof). Two cross positions for the cow were considered, A and B (fig. 1); longitudinal position was set at the middle of the barn.

The cow was simulated as an ellipsoid as follow: $x^{2} / a^{2}+y^{2} / b^{2}+z^{2} / c^{2}=1$, where $a$ is the half of the cow length, $b$ is the half of the cow width, $c$ is the half of the trunk height. Ellipsoid area surface was 5.46 $\mathrm{m}^{2}$, very close to that obtained with the well known formula for Holstein cows, weighing $600 \mathrm{~kg}$, that is: $\mathrm{A}_{\text {cow }}=0.14 \times \mathrm{W}^{0.57}=5.37 \mathrm{~m}^{2}[1]$.

Heat exchanged between any cow and the roofing pitch was calculated by the following [11]:

$Q_{r-c o w_{j}}=\frac{\sigma\left(T_{r}^{4}-T^{4} \text { coat }\right)}{\frac{1-\varepsilon_{r}}{\varepsilon_{r} A_{T}}+\frac{1}{A_{r} \cdot F_{r-c o w}}+\frac{1-\varepsilon_{c o w}}{\varepsilon_{c o w} A_{c o w}}}$

where $\mathrm{Q}_{\mathrm{r} \text {-cowj }}(\mathrm{W})$ is the heat exchanged between the roofing ( $\mathrm{r}=$ pitch $\mathrm{R} 1$ or $\mathrm{R} 2$ of fig. 1) and the cow in the $j$ position (A or B of fig. 1), $\mathrm{T}_{\mathrm{r}}$ is the internal surface temperature of the roofing $(\mathrm{K}), \mathrm{T}_{\text {coat }}$ is the surface temperature of the cow fur $(\mathrm{K}), \mathrm{A}_{\mathrm{r}}$ is the roof area of the considered pitch $\left(\mathrm{m}^{2}\right), \mathrm{F}_{\mathrm{r} \text {-cowj }}$ is the view factor between the roof (pitch R1 or R2) and the cow, $A_{\text {cow }}$ is the body surface area of the cow $\left(\mathrm{m}^{2}\right), \varepsilon_{\mathrm{r}}$ and $\varepsilon_{\text {cow }}$ are, respectively, the emission coefficient of the 

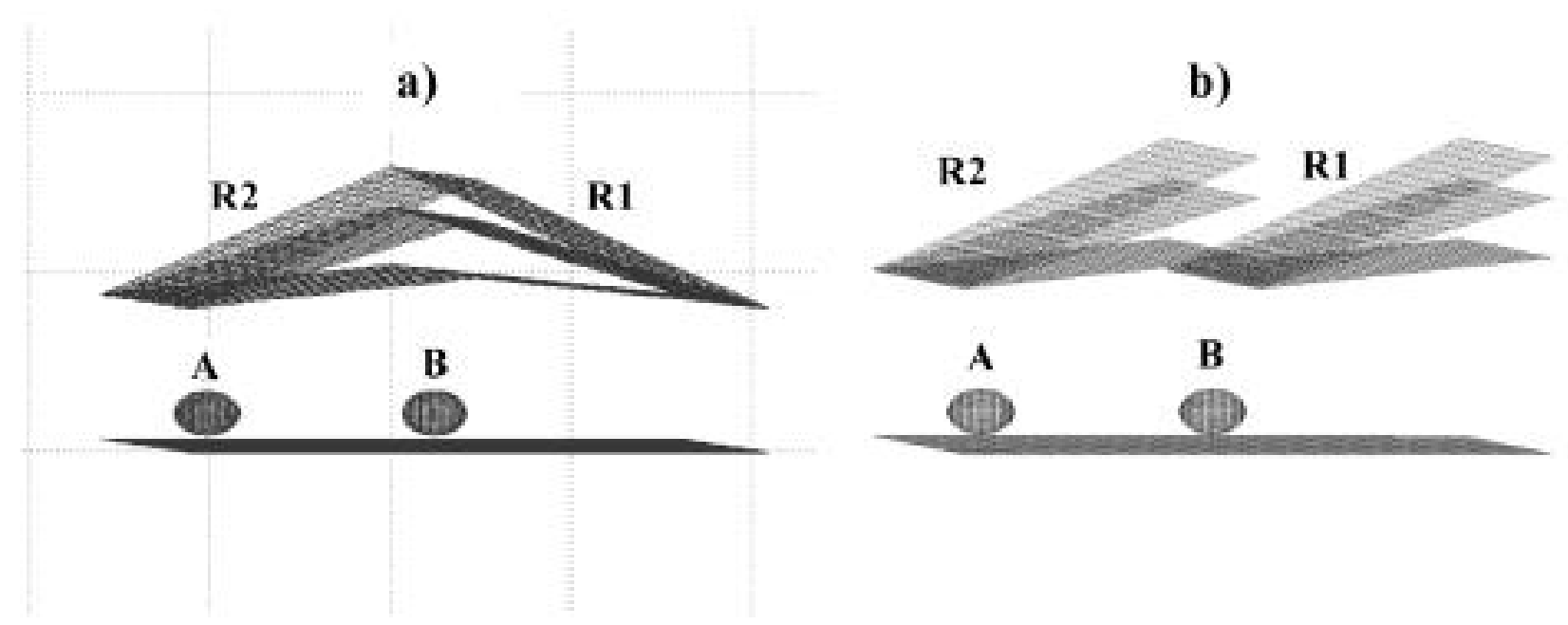

Fig. 1 - Roof configurations: a) gabled roof; b) multiple shed roof. A and B, the cow positions inside the barn considered for the view factor calculation. Three roof slope (10, 30 and $45 \%)$, and two eaves height ( $3.5 \mathrm{~m}$ and $4.5 \mathrm{~m})$ were evaluated. R1 and R2 are the roofing pitches.

roof (set at 0.9 ) and the cow (set at 0.98 ); $\sigma$ is the Stefan-Boltzmann constant. $\mathrm{Q}_{\mathrm{r}-\mathrm{cowj}}$ will be positive when the cow is absorbing heat, and negative when the cow is releasing heat.

\subsection{Determination of the inside surface temperature of the roof $(\mathrm{Tr})$}

The model developed to calculate Tr was dynamic and took into account all aspects affecting the internal environment. Shortly, the inputs were: building geometry, building orientation, vent opening (size and position), thermal-inertial characteristics of constructive materials (thermal conductivity, density, specific heat capacity, heat transfer coefficients), walls layering, terrestrial coordinates (longitude, latitude), type of the housed animals (species, live weight and age), as well as local climatic conditions (direct and diffuse solar radiation, wind speed and direction, air temperature and humidity). For a detailed description of the model see [8].

Roof contribution was determined considering its internal surface temperature, evaluated by modelling the thermal behaviour by means of a one-dimensional
Fourier equation solved through the finite difference method.

The boundary conditions at the outside roof surface consider the solar radiation, both direct and diffuse, the convective exchange, and the radiative sky vault exchange. Sun position in the sky was updated at each calculation step (time step set @ 1 min); the incident radiation was calculated according to the building orientation.

\subsection{Calculation of the view factor and the coat surface temperature}

To calculate the view factors under different conditions a computer program was expressly developed in Matlab ambient. After a meshing step regarding both the roof and the cow, the view factors were calculated using the discretized version of the following formula [11]:

$F_{r-\operatorname{con} v}=\frac{1}{A_{r}} \int_{A_{r}} \int_{A_{\text {cow }}} \frac{\cos \left(\alpha_{\text {cow }}\right) \cos \left(\alpha_{r}\right)}{\pi r^{2}} d A_{\operatorname{cow}} d A_{r}$

where $\mathrm{F}_{\mathrm{r}-\mathrm{cow}}$ is the view factor between the roof and the cow, $A_{r}$ is the area of the roof $\left(\mathrm{m}^{2}\right), \varepsilon_{\text {cow }}$ and $\varepsilon_{\mathrm{r}}$ are
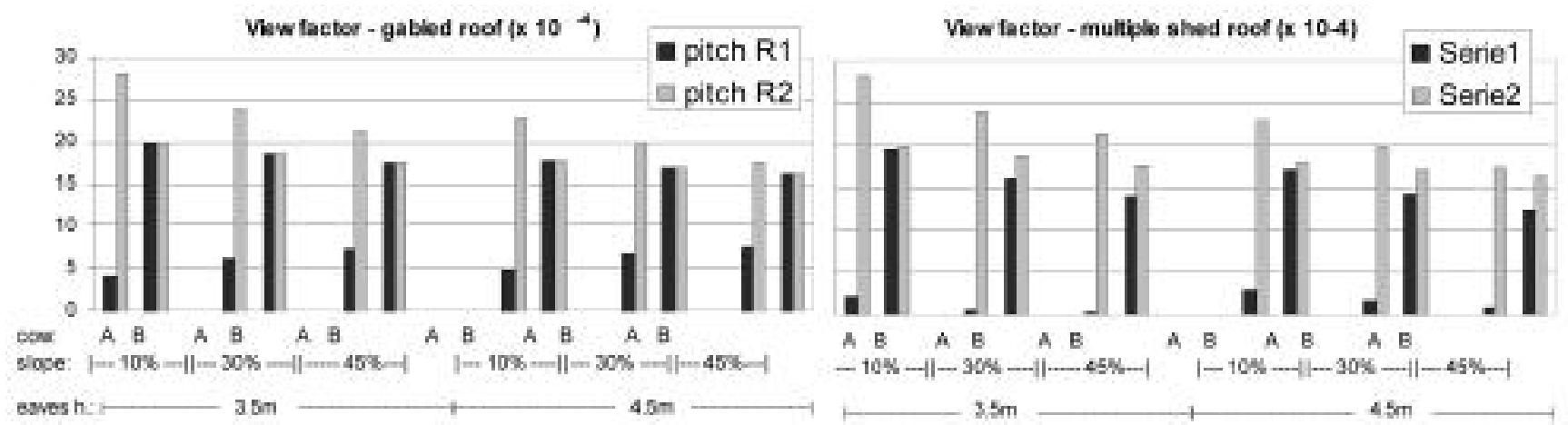

Fig. 2 - View factors $\left(\mathrm{F}_{\mathrm{r}-\mathrm{cow}}\right)$ for cows in A and B position, with respect of each pitch, for gabled and multi shed roof shapes. 
the angles (rad) between the normal to each elementary face $\mathrm{dA}$ and the connecting straight line of the two faces centres; $r$ is the distance between the faces $\left(\mathrm{m}^{2}\right)$.

The code was validated by comparing the results obtained from several view factor configurations having analytical solution.

For each cow position, the view factor was calculated to each of the two roof pitches. So, for example, with a cow in A position, two view factors were calculated: FR1-A, and FR2-A. The calculated view factors for all configurations are reported in fig. 2 .

To calculate $\mathrm{T}_{\text {coat }}$ of the cow fur as a function of the internal air temperature, the work of Turnpenny et al. [13] was considered. In particular, a linear function $\mathrm{T}_{\text {coat }}=\mathrm{f}\left(\mathrm{T}_{\text {air }}\right)$ was constructed considering two points: 1) $\mathrm{T}_{\text {coat }}=19^{\circ} \mathrm{C}$ with $\mathrm{T}_{\text {air }}=15^{\circ} \mathrm{C}$ and 2) $\mathrm{T}_{\text {coat }}=30.4^{\circ} \mathrm{C}$ with $\mathrm{T}_{\text {air }}=30^{\circ} \mathrm{C}$. That is, the gradient $\mathrm{T}_{\text {coat }}-\mathrm{T}_{\text {air }}$ is decreasing as $\mathrm{T}_{\text {air }}$ is increasing.

Two building orientations were tested (NS, WE), with an insulated roofing (fibre-cement plus $4 \mathrm{~cm}$ of polystyrene) and without insulation (only fibre-cement). Furthermore two roof shapes (gabled and multi shed), three slopes $(10 \%, 30 \%$ and $45 \%)$ and two eaves heights ( $3.5 \mathrm{~m}$ and $4.5 \mathrm{~m}$ ) were tested (fig. 1 ).

\section{Results and discussion}

\subsection{Instantaneous thermal power exchanged between the cow and the roofing}

The instantaneous net balance of the radiative thermal power exchanged between a cow in B position and a gabled roof is reported in figure 3 . The heat gained at the peak value by the cow with a non-insulated roof is 4-5 times greater than with the insulated roof, even if the heat lost by the cow is greater with the non-insulated roof (but less than one time, in the best configuration).

To evaluate the response of the different configurations and cow positions, we refer to the figures 4 and 5 , which report the peak values of the instantaneous net power balance at the cow surface (positive and negative, respectively for cow absorbing and releasing heat), with the cow in A or B position).

Comments concerning the thermal roof behaviour will be done with respect to different affecting factors: roof shape, insulation, orientation, eaves height, cow location inside the barn.

To improve the readability of the observations, the following abbreviations will be adopted:

$\mathbf{G R}=$ gabled roof;

$\mathbf{S R}=$ shed roof;

$\mathbf{A}, \mathbf{B}=$ cow in A or B position (see fig. 1);

NS, WE = building orientation;

$10 \%, 30 \%, 45 \%$ = roof slope;

PPB, NPB = Positive or Negative thermal Power Balance at the cow level (peak values). Also the period related to this specific balance conditions (see fig. $3)$.

I.e., GR-A_45\%, refers to a cow located in A position under a gabled roof with a slope of 45\%; A_10\%_WE refers to a cow in A position, roof slope $10 \%$ and WE oriented.

\section{The insulation factor}

Clearly, roof insulation is the most important factor to reduce the heat load on the cow. But insulation can prevent the heat loss from the cow itself during night time.

Passing from an insulated roof to a non-insulated one we have the following:

$P P B$ period

With GR-B_45\% insulated, PPB is only $18 \mathrm{~W}$, rising
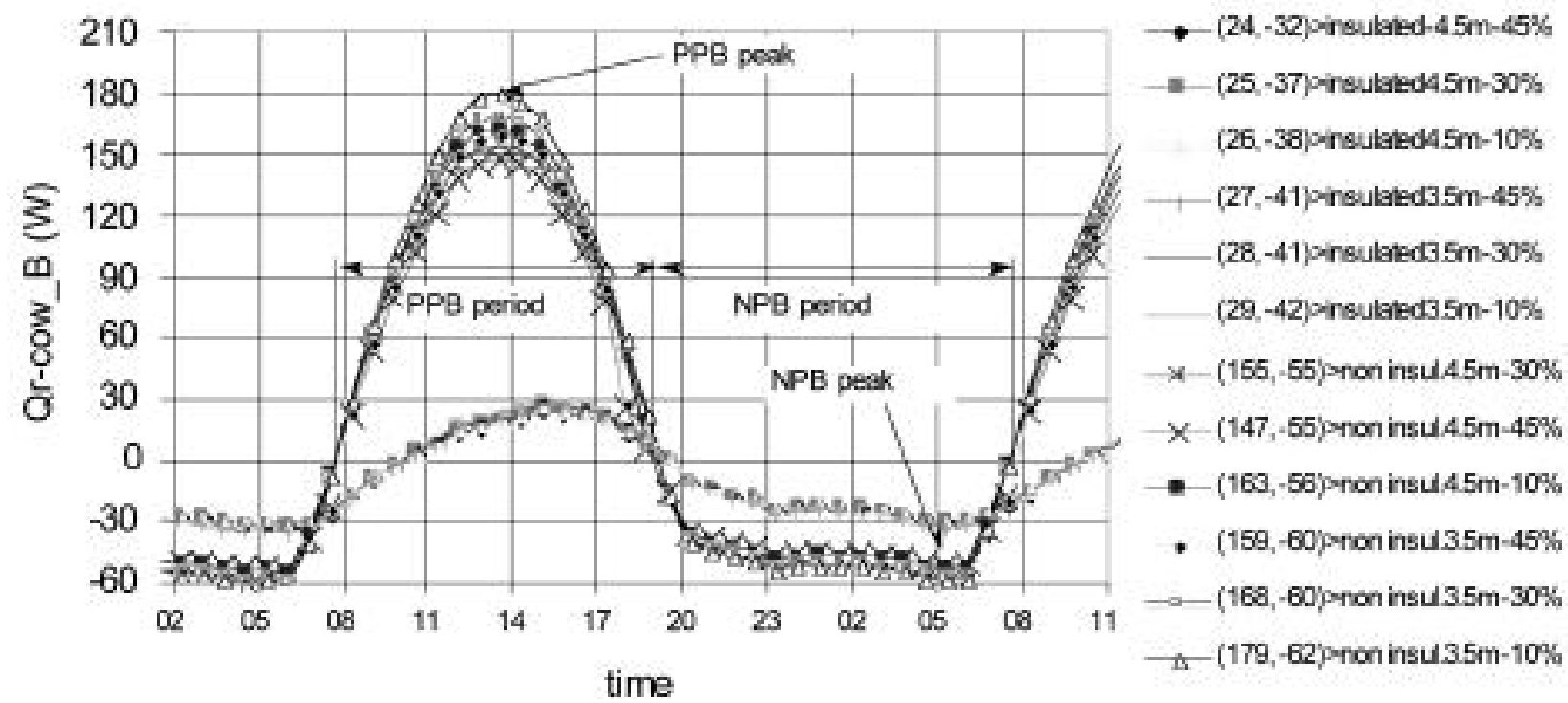

Fig. 3 - Gabled roof. Instantaneous thermal power exchanged between the roof and the cow in B position, for WE orientation, with different roof configurations. In the legend, within parentheses are the positive and negative peak values (PPB, NPB = Positive or Negative thermal Power Balance, and the related period, indicated in the figure only for the non-insulated roof). 


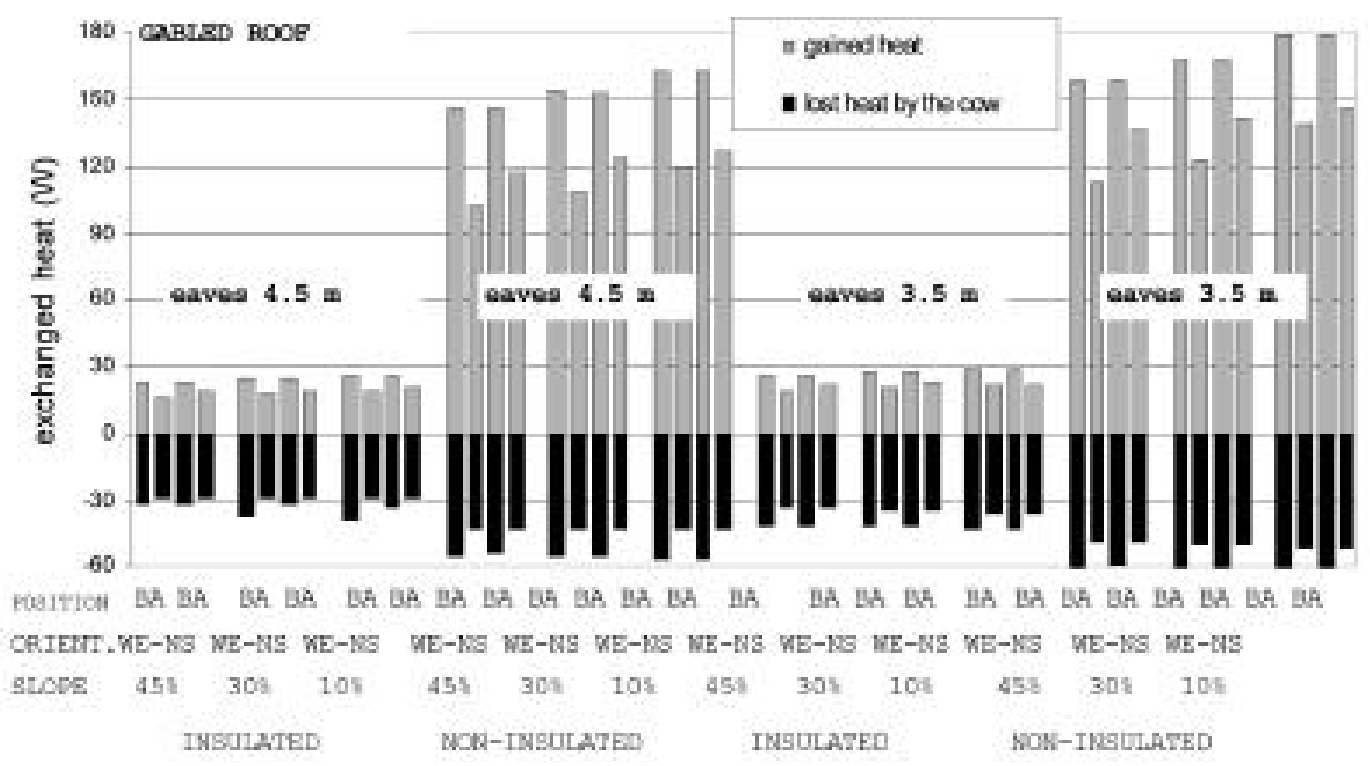

Fig. 4 - Gabled roof. Thermal power (peak values) exchanged by the cow trough the roof (positive if gained and negative if lost by the cow), for different roof configurations.

up to $98 \mathrm{~W}$ without the insulation $(+512 \%)$, about the same with the cow in A position and a slope of $10 \%$.

With SR, passing from an insulated to a non-insulated roof, the response is differentiated, depending on the orientation: with WE PPB increases of $463 \%$ ( $511 \%$ for a $10 \%$ slope), up to $700 \%$ for NS orientation (505\% for $10 \%$ slope). NPB period

In this context, passing from an insulated to a noninsulated roof we see higher heat losses from the cow. In particular, in GR_45\% we pass from $32 \mathrm{~W}$ to $55 \mathrm{~W}$ ( $+72 \% ;+48 \%$ in A position), about the same for both WE and NS orientations and for a slope of $10 \%$.

With SR, improvement for A position is the same than in GR, and reduced for B position (46\%, passing from $22 \mathrm{~W}$ to $48 \mathrm{~W}$ ).

In other words, the insulation reduces the PPB, but also the NPB. However the advantage of insulation in the diurnal period is much bigger than in the night period. Slope and orientation are not important in GR, while in SR, passing from a slope of $10 \%$ to $45 \%$, PPB is reduced of $25 \%$. With insulation, $A$ is better than B (PPB is reduced of $25 \%$ up to $38 \%$ with slope of $45 \%)$.

\section{The roof shape factor}

Roof shape (gabled and shed) is important, much more with greater roof slopes.

Passing from GR to SR the cow reduces its PPB, but also the NPB during the night time.

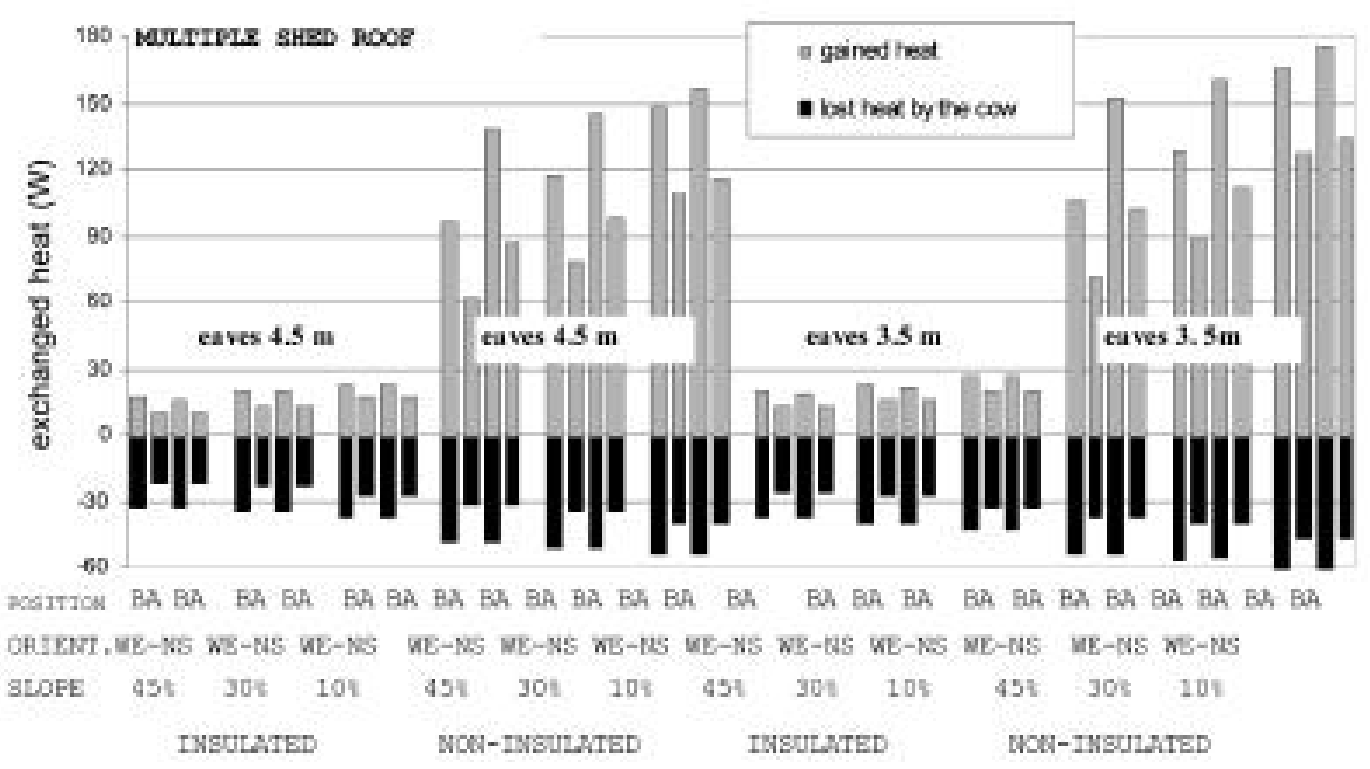

Fig. 5 - Multiple shed roof. Thermal power (peak values) exchanged by the cow trough the roof (positive, gained, negative lost by the cow), for different roof configurations. 


\section{PPB period}

for insulated roof:

Passing from GR_45\% to SR_45\%, a cow located in B position reduces the PPB of about $25 \%$ (both for NS and WE orientations), passing from $24 \mathrm{~W}$ to $18 \mathrm{~W}$. In the A position, there is an ulterior PPB reduction, which depends on building orientation: with WE the reduction is of $35 \%$ (from $17 \mathrm{~W}$ to $11 \mathrm{~W}$ ), while with NS the reduction is $45 \%$ (from $17 \mathrm{~W}$ to $9 \mathrm{~W}$ ).

With a slope of $10 \%$, passing from GR to SR we have the following reductions: B_10\% $=9 \%$ both for WE and NS; A_10\%_WE $=11 \%$, A_10\%_NS $=14 \%$.

for non-insulated roof:

The reduction, passing from GR to SR_B_45\% WE, is of $33 \%$ (only $5 \%$ for NS orientation), from $147 \mathrm{~W}$ to $98 \mathrm{~W}$. With a cow in A position, we have a reduction from GR to SR_A_45\% of $39 \%$ (25\% for NS orientation); with the slope at $10 \%$, the improvement (reduction of PPB) is, for all the configurations, of about $9 \%$.

\section{$N P B$ period}

for insulated roof:

For the B position, the roofing does not show particular differences, both for $45 \%$ and $10 \%$ slopes (about $38 \mathrm{~W}$ ). When cow in the $A$ position, NPB passes from $29 \mathrm{~W}(\mathrm{GR})$ to $21 \mathrm{~W}$ (SR) with a slope of $45 \%$, while with roof slope of $10 \%$ the worsening is only of $7 \%$.

for non-insulated roof:

In B position, passing from GR to SR the worsening is of $13 \%$ (passing from $55 \mathrm{~W}$ to $48 \mathrm{~W}$ with WE orientation), greater with NS orientation $(26 \%)$, like in A position (from $42 \mathrm{~W}$ to $31 \mathrm{~W}$, both for WE and NS orientations)

So, if the SR improves the situation during the daytime (the reduction of the PPB is up to $45 \%$ ), in night time we have a general worsening (the reduction of the NPB is of 27\%). This behaviour of the roof is due to the fact that in the SR the view factor between the roof and the cow is lower than in GR.

Shortly:

With insulation, passing from GR to SR, PPB is reduced from $25 \%$ to $35 \%$ with a slope of $45 \%$ (only $10 \%$ with a slope of $10 \%$ ); also NPB is reduced ( $27 \%$ for SR-A_45\%, and less more with a slope of $10 \%$ ).

Without insulation, PPB is reduced of $33-40 \%$ with a slope of $45 \%, 9 \%$ with a slope of $10 \%$. Also NPB goes down, more with a slope of $45 \%$ (13-26\%), less with a slope of $10 \%(4-7 \%)$.

\section{The building orientation factor}

Building orientation seems do not affect the response of insulated roofs.

For non-insulated roofs we have:

$P P B$ period

In GR-B position the orientation is not important, while in SR-A and B positions WE orientation is better than NS: PPB is reduced by $29 \%$ with a slope of $45 \%, 19 \%$ with a slope of $30 \%$, and $6 \%$ with a slope of $10 \%$.

\section{$N P B$ period}

Building orientation does not affect the response of the roof.
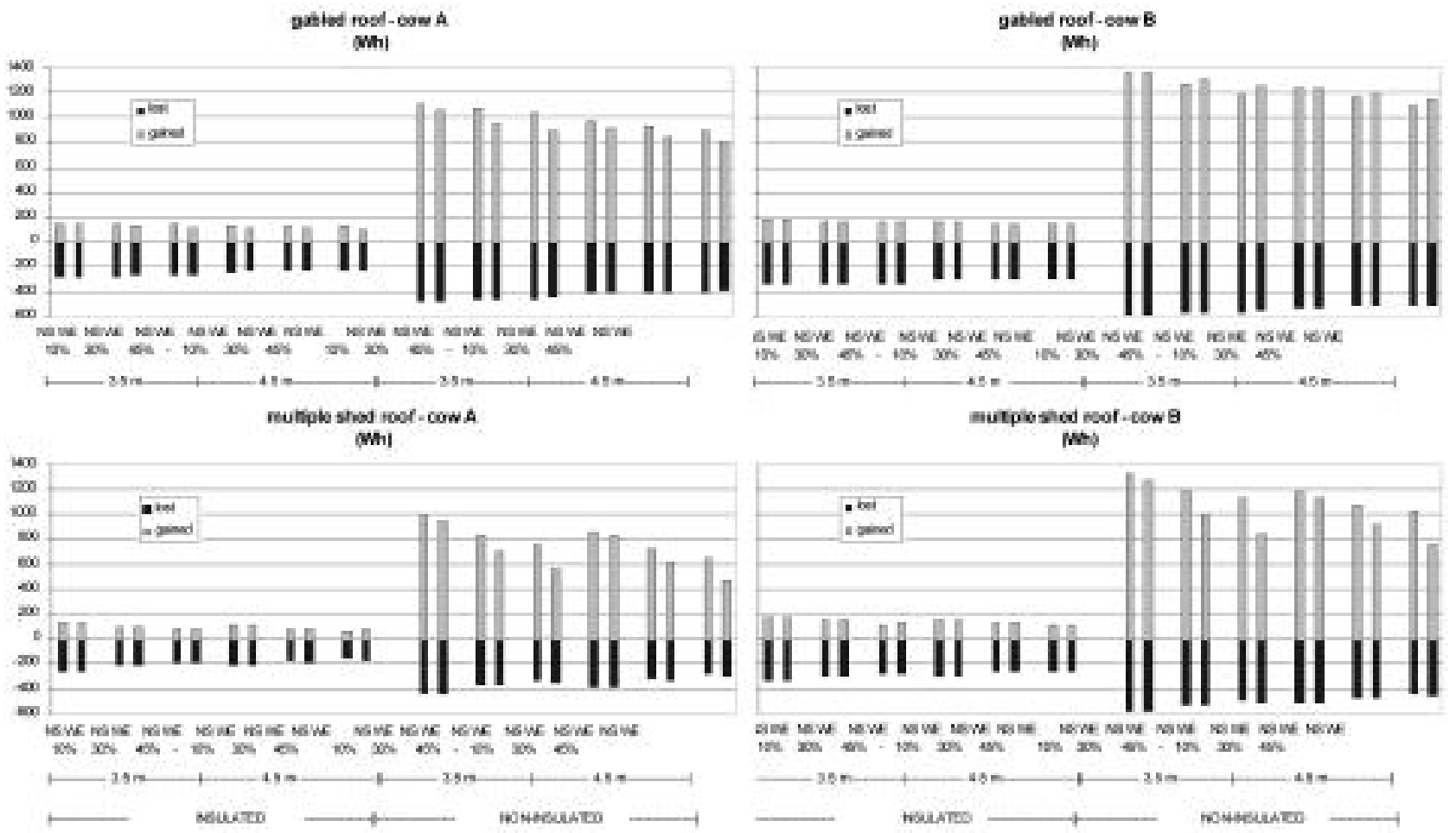

Fig. 6 - Thermal energy (Wh) exchanged by the cow and the roof, for different roof slope, building orientation, eaves height, with and without insulation, during daytime (positive values, heat gained by the cow over the PPB interval time) and night time (negative values, heat lost by the cow during the NPB interval time). 


\section{Eaves height factor}

The increasing of eaves height reduces the view factor; this fact on a side reduces PPB, but, on the other side, also reduces NPB. So, if increasing of the eaves height improves the daytime situation, night time conditions worsen.

With insulated GR and SR, passing from $4.5 \mathrm{~m}$ to $3.5 \mathrm{~m}$, PPB and NPB are reduced of about by $10 \%$.

For the considered heights of the eaves in this work, not so high, direct cow heat exchange with the sun and the sky vault should not be relevant.

Cow location inside the barn ( $A$ and $B$ positions) factor $\overline{P P B}$ period

In daytime A location is better than B location, and vice versa in night time, both in GR and in SR, insulated or non-insulated.

Meanly speaking, GR-A is $20 \%$ better than B, while SR-A is $27 \%$ better.

$N P B$ period

GR-B is $18 \%$ better than A, while SR-B is $30 \%$.

\section{The slope factor}

NPB worsens as slope is increased, due to the reduced view factor).

PPB period

Generally, in GR, if the slope increases from $10 \%$ to $45 \%$ PPB is reduced by $11 \%$. For the same increase slope, in SR-B_WE, we have an improvement of 20$16 \%$. With SR-A_WE, we have $28-21 \%$.

With NS the improvement is reduced. $N P B$ period

In night time the thermal behaviour of the building does not depend on the orientation, but only from the view factor, increasing with decreasing of the slope. GR does not present any variation. In SR-B, passing from $10 \%$ to $30 \%$ in the slope NPB is reduced by $7 \%$.

\subsection{Exchange of energy}

Time duration of PPB and NPB periods is not equivalent. In particular, with a non-insulated roof the PPB period begins early in the morning (at about 8 am, figure 3), before than in an insulated roof (10 am), but terminates only short before (about half an hour before). The NPB period begins before with the non-insulated roof (just half an hour), and terminates before.

So, the PPB period is meanly $9.4 \mathrm{~h}$ for the insulated roof, and $11.7 \mathrm{~h}$ for the non-insulated one, while the NPB period is $14.6 \mathrm{~h}$ for insulated and $12.3 \mathrm{~h}$ for non-insulated roof.

These difference in PPB and NPB duration make relevant the analysis of the energy exchanged in those periods. Figure 6 shows the integral of the thermal energy gained (positive) or lost (negative, black bars) by the cow during the 24 hours.

Generally speaking, increasing of the slope reduces the energy gained by the cow, and WE is the best ori- entation if cow located in position GR-A, SR-A and SR-B.

With respect to the heat lost by the cow, the best solution is with the non-insulated roof, a $3.5 \mathrm{~m}$ eaves height, and a slope of $10 \%$.

Normally, a lower view factor for a given roof configuration produces a better condition, reducing the PPB during daytime (considering roofs with the same degree of insulation). The view factor decreases when increasing the slope and the eaves height: SR shows the lower values (mainly due to the pitch R1), which are more pronounced with the cow in A position (fig. 2). A smaller view factor produces a smaller NPB.

GR is less affected than SR by parameters changing, and SR behaviour is generally better than GR. Generally speaking, insulated roofs show a similar behaviour (both for the GR and SR), although SR is better than GR.

Insulated roofs are the best solution for the lower net heat transferred to the cow. The best solution is: SR_45\%-4.5 m, with $75 \mathrm{Wh}$.

Referring to the cow position, $\mathrm{A}$ is better than $\mathrm{B}$ during the day; in night time, $\mathrm{A}$ and $\mathrm{B}$ are at the same level (both for GR and SR), while A was generally better than $\mathrm{B}$ considering also the exchanged power (see figures 4 and 5).

\section{Conclusions}

In this work only the radiative exchange between the roof and the cow has been considered. From this point of view, the evidence found is that insulating is the relevant factor to reduce cow heat load: this is particularly true for closed barns.

For open shade shelters, other aspects must be taken into account. For example, if the site where the shelter is located presents a good wind action level; in this case, non-insulated shelters could be adopted.

The non-insulated multi shed roof with a slope of $45 \%$ and an eaves height of $4.5 \mathrm{~m}$, oriented in WE, shows a peak in PPB of $98 \mathrm{~W}$ and a peak in NPB of $48 \mathrm{~W}$ for the $\mathrm{B}$ position; $62 \mathrm{~W}$ and $31 \mathrm{~W}$, respectively, for the A position The energy absorbed by the cow in $\mathrm{B}$ position during the PPB period is $770 \mathrm{Wh}(483 \mathrm{Wh}$ in A position). The heat released during the NPB period is $457 \mathrm{Wh}$, that is $60 \%$ of what gained in PPB period. This heat load could be not excessive if part of the heat produced by the cow can be removed by the convection way.

An ulterior aspect to be considered is the location of the cows inside the barn: in A position we have a reduction of the heat load of about $30 \%$.

\section{References}

[1] Berman A., Effects of Body Surface Area Estimates on Predicted Energy Requirements and Heat Stress. J. Dairy Sci. (2003) 86: 3605-3610.

[2] Bray D.R., Bucklin R.A., Montoya R. and Giesy 
R., Means to reduce environmental stress on dairy cows in hot, humid climates. Proc. Third International Dairy Housing Conference, Orlando, Florida, 2-5 February, (1994), 589-597.

[3] Bucklin R.A., Bottcher R.W., Van Wicklen G.L. and CZARICK M., Reflective Roof Coatings for Heat Stress Relief in Livestock and Poultry Housing. Applied Engineering in Agriculture (1993) 9 (1), 123129.

[4] Buffington D.E., SkinNer T.C., Solar Radiation and Wind effects as Functions of Building Orientation. Trans. ASAE, (1980) 23 (6), 1482-1488.

[5] Garret W.N., Bond T.E. and Pereira N., Influence of shade height on physiological responses of cattle during hot weather. Trans. ASAE, (1967) 10 (4), 156-167.

[6] Cascone G., Influenza della copertura sul microclima degli edifici zootecnici nell'area mediterranea. Atti del IV Convegno Nazionale A.I.G.R. su: "Ingegneria per lo sviluppo dell'agricoltura", Porto Conte (Alghero), 4-6 maggio 1988, 265-270.

[7] Liberati P., Zappavigna P., Performance of ventilated roofs in hot climate, International Symposium of the CIGR 2nd Technical Section, Evora, Portogallo, May 2-6, (2004), 1-8. CD N. FB04_611.

[8] Liberati P., ZaPpaVigna P., A computer model for optimization of the internal climate in swine housing design. Trans. ASABE. (2007) 50 (6), 2179-2188.

[9] Eppsson K.H., Gustafsson G., Solar Heat Load in Uninsulated Livestock Buildings, J. agric. Engn. Res. (2001) 78 (2), 187-197.

[10] Perry R.L., SPeCK E.P., Geometric factors for thermal radiation exchange between cows and their surroundings. Trans. ASAE. (1962) 5 (1), 31-37.

[11] ÖzışIK M.N., 1985. Heat Transfer: A Basic Approach. New York, N.Y.: McGraw-Hill.

[12] Swierstra D., van Ouwerkerk E.N.J., A model estimating the effectiveness of shade structures on the production of dairy cows in hot climates. Seminar of the $2^{\text {nd }}$ Technical Section of the CIGR Agricultural Buildings in Hot Climate Countries, Catania, Italy, September (1985).
[13] StOwell R.R., Bickert W.G., NuRnBerger F.V., Radiant Heating and Thermal Environment of Metal Roofed Dairy Barns. Proc. Fourth International Dairy Housing Conference, St. Louis, Missouri, (1998) 193-200.

[14] Turnpenny J.R., McArthur A.J., Clark J.A., WaTHES C.M., Thermal balance of livestock. 1. A parsimonial model. Agricultural and forest meteorology (2000) 101, 15-27.

[15] Zappavigna P., Liberati P., Thermal Behaviour of Animal Houses in Hot Climate: Experimental Contribution to the Theoretical Approach. Proc. ASAE Annual International Meeting and CIGR XVth World Congress, Chicago, USA, July (2002) 28-31: CD Paper.

[16] ZAPPAVIGNA P., LiBERATI P., Slotted roofs as a tool for improving the housing conditions in hot climate, Proceedings of the Seventh International Symposium "Livestock Environment VII" A.S.A.E., Beijing, China, 18-20 May (2005), 1-6, ISBN 1-892769-48-4.

\section{SUMMARY}

A simulation model determining the heat flow exchange between housed animals and the roofing was developed considering various relevant factors: constructive materials, slope, height, orientation, latitude, external air temperature, solar load, animal position.

Results show that the most important factor to reduce heat load is the insulation. For non-insulated roofing the slope and the orientation are the most relevant factors.

Considering the total exchanged energy, the non insulated roof has a good nocturnal global behaviour.

\section{Key words:}

roofing design, heat stress, dairy cows, view factor, simulation. 


\section{CONFERENCE}

\section{CONVEGNO NAZIONALE DI IDRAULICA E COSTRUZIONI IDRAULICHE (XXXII ITALIAN CONFERENCE OF HYDRAULICS AND HYDRAULIC CONSTRUCTIONS)}

The Conference will be held between September 14th and 17th 2010, with an open preliminary session reserved for young researchers on the afternoon of 13th. We invite you to submit papers whose topics are included within the following list, as established by the G.I.I. Scientific Council:

Topic A - New frontiers in Fluid Mechanics;

Topic B - Hydraulic and Maritime Constructions for risk mitigation and resource management;

Topic C - Modeling of hydraulics and hydrological phenomena;

Topic D - Techniques for monitoring environmental processes.

Each of these topics encompasses different "specialist sessions" whose list will be published in a further announcement. Final papers must be submitted by 1st March 2010, to allow a peer-review process by the Scientific Committee. The oral presentations will probably be limited in number in order to promote discussion and in-depth examination of the subjects discussed. The mode of presentation (as oral or poster) will be decided by the Scientific Committee. All papers that will be presented at oral and poster sessions will be published in the Proceedings of the Conference.

All further information will be published on the Conference website: www.idra2010.unipa.it 